\title{
Influence of Zeolite on fatty acid composition and egg quality in Tunisian Laying Hens
}

\author{
Imen Fendri ${ }^{1}$, Lamia Khannous ${ }^{1 \dagger}$, Zouhir Mallek ${ }^{2 \dagger}$, Al Ibrahim Traore ${ }^{3}$, Néji Gharsallahn ${ }^{4}$ and Radhouane Gdoura ${ }^{{ }^{*}}$
}

\begin{abstract}
Background: The health benefits of omega-3 and omega- 6 polyunsaturated fatty acids (PUFA) are generally recognized. Unfortunately, in most Mediterranean countries, the recommended daily intake of these compounds is rarely met. Therefore, enrichment of commonly occurring foods can boost intake of these fatty acids. In this regard, eggs are an interesting target, as they form an integral part of the diet.

Result: Zeolite (Clinoptilolites) was added to Laying Hens feed at concentrations 1\% or 2\% and was evaluated for its effects on performance of the production and on egg quality. The Laying Hens were given access to $110 \mathrm{~g}$ of feed mixtures daily that was either a basal diet or a 'zeolite diet' (the basal diet supplemented with clinoptilolite at a level of $1 \%$ or $2 \%$ ). It was found that zeolite treatment had a positive and significatif $(p<0.05)$ effect on some parameters that were measured like egg height and eggshell strength. While dietary zeolite supplementation tended to/or has no significant effects on total egg, eggshell, yolk and albumen weights. It was found also that zeolite mainly increases level of polyunsaturated fatty acids in egg.

Conclusion: This study showed the significance of using zeolite, as a feed additive for Laying Hens, as part of a comprehensive program to control egg quality and to increase level of polyunsaturated fatty acids on egg.
\end{abstract}

Keywords: Zeolites, Egg production, Eggshell quality, Laying hen, Fatty acids

\section{Background}

Natural zeolites mining which are easier and cheaper than other mines are found in large reserves [1]. It has been known that zeolites are crystalline, hydrated aluminosilicates of alkali and alkaline earth cations, consisting of three-dimensional frameworks of $\mathrm{SiSO}_{4}^{4-}$ and $\mathrm{AlO}_{4}^{5-}$ tetrahydralinked through the shared oxygen atoms $[2,3]$. They have the ability to lose and gain water reversibly and to exchange constituent ionic cations without major changes of structure [4-6].

The exploitation of these properties underlies the use of zeolites in wide range of industrial and agricultural applications and particularly in animal nutrition since mid1960s [2]. Reviews on the chemistry and applications of zeolits in agriculture are given by Mumpton and Fishman [4]. They reported that both ion exchange and absorption properties of natural zeolites can be used to make more

\footnotetext{
* Correspondence: gdourar@yahoo.com

${ }^{\dagger}$ Equal contributors

'Unité de recherche Toxicologie - Microbiologie Environnementale et Santé (UR11ES70), Faculté des Sciences de Sfax, Université de Sfax, Sfax, Tunisia Full list of author information is available at the end of the article
}

efficient use of feed nitrogen in animal nutrition, to reduce intestinal disease in pigs and ruminants and to control the moisture content of animal manure. In this regard, Onogi feeding up to $10 \%$ clinoptiolite-tuff in the diet of Leghorm chickens found no significant difference with regard to mortality but found that mass gain feed efficiency were improved on the clinoptiolite diets [7]. He concluded that zeolite should be used to economize on the feed and reduce the moisture content of chicken dropping.

Others studies suggest that dietary zeolites improves weight gain of fatting pigs, feed efficiency and egg production in laying hens $[1,8]$. These substances were also found to absorb various mycotoxins [2]. In addition, zeolite has been shown to be a beneficial feed additive that exhibits a strong preference for binding nitrogenous cations like $\mathrm{NH}_{4}^{+}$and $\mathrm{NH}_{3}$ emission [9]. This property has made it in attractive option for a variety of applications in the treatment of livestock and poultry wastes. Zeolite has been investigated as both a livestock, feed additive and a topical manure additive to adsorb $\mathrm{NH}_{3}$. Forms of zeolite have been used to remove ammonium from aqueous solutions [10] and help in reducing ammonia production by pullets

\section{Biomed Central}


and laying hens [9] and in broiler houses [11]. It is important to remove ammonia from poultry houses since it has been reported that high atmospheric ammonia in poultry facilities has been linked to damage respiratory tract lining, reduced resistance to respiratory diseases, increased ascites and lower performance [12].

Previous work [13] has shown that Zeolite, when added as feed additive in Tunisian broilers, influences positively meat structure and on the production of omega 3 polyunsaturated fatty acids. It is important to note that food enrichment is probably the best long-term solution to boost intake of long chain $\mathrm{n}-3$ polyunsaturated fatty acid (PUFA) [14]. An interesting route is n-3 PUFA enrichment of eggs through dietary supplementation of laying hens. The laying hen provides a model for conducting large-scale dietary intervention studies with statistically significant numbers of animals [15].

Omega- 3 and omega- 6 fatty acids are polyunsaturated fats that are essential fatty acids because they cannot be synthesized by the body and must be obtained from the diet [15]. Omega 3 fatty acids have been shown to reduce inflammation and help prevent risk factors associated with chronic diseases such as heart disease, cancer, and arthritis [15]. Omega 3 fatty acids also appear to be important for proper brain and behavioral functions [15]. Epidemiologic studies indicate that populations that consume high amounts of Omega 3fatty acids have lower incidences of breast, prostate, and colon cancers than do those that consume lower amounts of Omega 3 fatty acids [16-18].

Typically, the amount of saturated or monounsaturated fatty acids in eggs is hardly influenced by the lipids in the feed [19]. In contrast, the PUFA content and profile in the egg can be modified through dietary supplementation.

In this regard, a traditional n-3 PUFA source to be added to hens' diet is flaxseed, a plant source rich in $\alpha$ linolenic acid. Alternatively, hens are often fed fish oil, which is rich in long chain n-3 PUFA eicosapentaenoic acid (EPA) and docosahexaenoic acid (DHA). A more recent trend is feed supplementation with microalgae as a source of EPA and/or DHA. As previously reported, Mallek et al. showed a positive effect of zeolite on PUFA production in broilers [13].

The objective of this study is so to examine the influence of natural zeolites, givens as supplement to laying hens feed on the fatty acid composition and on characteristics of eggs.

\section{Materials and methods}

\section{Zeolite composition}

Turkish Manisa Gödes zeolite, obtained from Rota Minnig Corporation (Istanbul, Turkey), was used in the present work. Clinoptiolite was the predominant mineral (84\%) present in the natural zeolite used as an active substance, at a moisture level of max. 6\%. It also contains $65 \%$ of $\mathrm{SiO}_{2}, 12 \%$ of $\mathrm{Al}_{2} \mathrm{O} 3,2.3 \%$ of $\mathrm{Fe}_{2} \mathrm{O} 3$ and $2.7 \%$ of $\mathrm{CaO}$ (Table 1). Particle size varies in a range of $0.2-0.5 \mathrm{~mm}$.

\section{Preparing of foods}

The basal food used in the study is standard powdered containing corn and soybean added with mineral vitamin complement (MVC) (Table 2). The food was obtained from SOMEPA factory (Tunisia). Different rations were prepared by adding zeolite at a weight of $0 \%$ (control), $1 \%$ and $2 \%$ food, respectively.

\section{Experimental step}

A total of 90/60 week-old Babcock B-300 layers hens were used in this study. They were put at random into 3 treatment groups (30 laying hens/group). The first group was used as a control group and had provided a feed without zeolite. The second and the third groups had provided with 1 and $2 \%$ of zeolite respectively. Layers hens were placed in wire cages $(23 \times 50 \times 42 \mathrm{~cm})$. Experiment was conducted in a three-tier cage system with 3 birds in each cage. They were placed in a deep pit house, ventilated both naturally and mechanically, and illuminated both artificially and naturally through windows. The Laying Hens were given access to 110 g of feed mixtures daily. The experimental measure for each group began after 15 days. 30 eggs were taken at random to the laboratory for the determination of egg quality. The animal protocols were approved by the Animal Research Panel of the Committee on Research Practice of the Sidi Thabet Veterinary School in Tunisia.

Table 1 Semi-quantitative mineralogical composition and chemical microanalysis of the natural zeolite, which was added in the diet

\begin{tabular}{ll}
\hline Chemical Component & \%WT \\
$\mathrm{SiO} 2$ & $65-71.3$ \\
$\mathrm{Al} 2 \mathrm{O} 3$ & $11.5-13.1$ \\
$\mathrm{CaO}$ & $2.7-5.2$ \\
$\mathrm{~K} 2 \mathrm{O}$ & $2.2-3.4$ \\
$\mathrm{Fe} 2 \mathrm{O} 3$ & $0.7-1.9$ \\
$\mathrm{Mg} O$ & $0.6-1.2$ \\
$\mathrm{Na} 2 \mathrm{O}$ & $0.2-1.3$ \\
$\mathrm{TiO} 2$ & $0.1-0.3$ \\
Mineralogical Component & $\%$ WT \\
Clinoptilolite & 84 \\
Cristobalite & 8 \\
Feldspar & 4 \\
Illite & 4 \\
Quartz & Traces \\
Carbonated minerals & $<0.5$ \\
\hline
\end{tabular}


Table 2 Composition of feed mixtures (\%) added with mineral vitamin complement (MVC) Nutritional values of diet

\begin{tabular}{ll}
\hline Nutrients & $\%$ \\
\hline Protein & 18 \\
Cellulose & 3,3 \\
Fat & 2,9 \\
Energy (Kcal/kg) & 2800 \\
Met & 0,4 \\
Lys & 0,8 \\
Cys & 0,73 \\
Ca & 3,5 \\
P & 0,55 \\
\hline
\end{tabular}

\section{Determination of egg quality}

The determination of egg quality was carried out by measuring egg length, shell breaking strength, weights of egg, shell, yolk and albumen. All measurements are duplicated and values averages are given.

\section{Determination of egg length}

The length of each egg was measured to the nearest $0.01 \mathrm{~mm}$ with a Cal electronic digital caliper (Mode 6" Digital Caliper Electronic).

\section{Determination of shell breaking strength}

The shell breaking strength was measured using a texturometer (Texture Analyser, TA Plus, LLOYD Instruments, England) as reported methods described by Hidalgo et al. [20].

\section{Determination of percentage shell}

The shell percentage was determined using the following formula:

$$
\text { Shell }(\%)=(\text { Shell weight }(\mathrm{g})) /(\text { Egg weight }(\mathrm{g}) \times 100)
$$

Weight measurement was carried out using a professional scale with precision $0.001 \mathrm{~g}$ (Sartorius BP $110 \mathrm{~S}$ ).

\section{Determination of yolk/albumen ratio}

Collected eggs were broken to determine albumen weight and yolk weight. Ratio yolk/albumen was determined using following formula:

$$
\text { Ratio yolk/albumen }=\frac{\text { yolk weight }}{\text { Albumen weight }}
$$

\section{Fatty acid composition}

Total lipids for fatty acid analysis were extracted from 5-g aliquot samples of thigh according to Folch et al. [21-24]. Fatty acid methyl esters (FAME) were prepared according to Wang et al. [25], and measured by gas chromatography of FAME in a Chrompack CP 900 apparatus fitted with a flame ionization detector. Analytical gas chromatography was carried out on a Hewlett-Packard 6890 gas chromatograph series II (Agilent Technologies, Palo Alto, California, USA) equipped with HP Innowax (30 m x $0.25 \mathrm{~mm}$, $0.25 \mathrm{ml}$ film thickness) capillary column. Each sample was injected with a split ratio of $1: 100$ and a continuous flow rate of $1.5 \mathrm{ml} / \mathrm{min}$ of chromatographic grade helium was used. The oven temperature was initially held for $20 \mathrm{~min}$ at $165{ }^{\circ} \mathrm{C}$, ramped at $5{ }^{\circ} \mathrm{C} / \mathrm{min}$ up to $240{ }^{\circ} \mathrm{C}$ and held isothermal for $25 \mathrm{~min}$. Injector and FID detector temperature were held at $250{ }^{\circ} \mathrm{C}$. FAMEs were identified by comparison of their retention time with respect to pure standard purchased from Sigma and analyzed under the same conditions. FAMEs were quantified according to their percentage area, obtained by integration of the peaks. The results were expressed as a percentage of individual fatty acids in the lipid fraction as described by Pordomingo et al. [26].

Main individual fatty acids were grouped in saturated fatty acids $($ SFA $=$ myristic $(\mathrm{C} 14: 0)+$ palmitic $($ C16:0 $)+$ stearic $(\mathrm{C} 18: 0))$, monounsaturated fatty acids (MUFA = myristoleic $(\mathrm{C} 14: 1)+$ palmitoleic $(\mathrm{C} 16: 1)+$ oleic $(\mathrm{C} 18: 1))$ and polyunsaturated fatty acids (PUFA $=n-3+n-6$ fatty acids), $\mathrm{n}-3$ fatty acids (linolenic (C18:3) + eicosapentaenoic $($ EPA; C20:5) + docosapentaenoic (C22:5; DPA) + docosahexaenoic (DHA; C22:6), n-6 fatty acids (linoleic (C18:2) + di-homo-gamma-linolenic (DGLA; C20:3) + arachidonic $(\mathrm{AA} ; \mathrm{C} 20: 4)+$ docosatetraenoic (adrenic; C22:4). In this study, only SFA, palmitoleic and oleic MUFA and linoleic and linolenic PUFA (among Omega 6 and Omega 3 groups respectively) were analyzed.

\section{Results and discussion}

Determination of egg quality at experimental step

The quality of egg produced from different laying hens groups was realized measuring the variation of egg length, variation of percentage shell, variation of breaking shell strength, yolk and albumen weights and the ratio yolk/albumen.

\section{Variation of egg length}

Variation of egg length was determined for the different rations tested (control laying hens and those that were fed on $1 \%$ and $2 \%$ of zeolite). Determination of egg length was carried out and results represented in Table 3 show a significant increase of egg length mainly when $1 \%$ of zeolite was added. In this regard, others studies report the effect of this mineral, added on animal food, on egg production [27]. 
Table 3 Effect of zeolite addition on egg height, eggshell weight and eggshell strength

\begin{tabular}{|c|c|c|c|}
\hline & Control & 1\% Zeolite & 2\% Zeolite \\
\hline Egg height (cm) & $6.052 \pm 0.248$ & $6.605 \pm 0.838^{\mathrm{bd}}$ & $6.216 \pm 0.247^{b}$ \\
\hline Eggshell weight (g) & $6.65 \pm 0.941$ & $6.73 \pm 0.823$ & $6.31 \pm 0.718$ \\
\hline Eggshell Strength (N/m) & $32.96 \pm 0.29$ & $37.01 \pm 0.55^{c}$ & $38.6 \pm 0.54^{c}$ \\
\hline
\end{tabular}

Each value is the mean of three determinations followed by standard deviation.

${ }^{\text {a }}$ Significant differences between the control/1\% Zeolite and control/2\%

Zeolite $\mathrm{p}<0.05$.

${ }^{b}$ Significant differences between the control/1\% Zeolite and control/2\% Zeolite $\mathrm{p}<0.01$.

' Significant differences between the control/1\% Zeolite and control/2\% Zeolite $\mathrm{p}<0.001$.

${ }^{\mathrm{d}}$ Significant differences between $1 \%$ Zeolite/2\% Zeolite $\mathrm{p}<0.05$.

\section{Effect of zeolite on eggshell weight and shell strength}

The result of variation of shell strength for the different rations tested was represented in Table 3. The shell strength was significantly increased $(p<0.001)$ after of addition zeolite in feed laying hens. These results are in agreement with the finding of Olver [28]. Authors reported, since 1989, that adding zeolite to the diet of poultry improves the process of egg shells strength without deleterious effects on the contents of the egg itself [28].

\section{Variation of egg weight, yolk and albumen weights}

Table 4 shows the variation of egg weight, yolk and albumen weights measured at different rations tested in this work. A slight increase of egg weight was observed when $1 \%$ of zeolite was added. Results show also a positive effect of zeolite on albumen weight. $1 \%$ seems to be the best concentration of zeolite added in feed which increase albumen mass to about $2 \%$ comparing with control albumen mass. However, results indicate that zeolite has no significant effect on yolk mass when $1 \%$ of zeolite was added and a slight increase of yolk mass $(\mathrm{p}<0.05)$ after addition of $2 \%$ of zeolite. Kermanshahi et al. [29] reported in previous work that natural zeolite has no significant effect effect on mass's yolk or mass's albumen

Table 4 Effect of zeolite addition on egg, yolk and albumen weights and on the ratio yolk/albumen

\begin{tabular}{lccc}
\hline & Control & 1\% Zeolite & 2\% Zeolite \\
\hline Total egg weight (g) & $63.62 \pm 5.965$ & $68.18 \pm 6.983^{\text {a }}$ & $66.83 \pm 5.561$ \\
Egg yolk weight $(\mathrm{g})$ & $22.82 \pm 2.595$ & $23.4 \pm 2.92$ & $24.5 \pm 2.585^{\mathrm{a}}$ \\
Egg albumen weight $(\mathrm{g})$ & $34.15 \pm 4.341$ & $38.04 \pm 4.724^{\mathrm{b}}$ & $36.02 \pm 3.85$ \\
Ratio Yolk/albumen & $0.68 \pm 0.11$ & $0.62 \pm 0.08^{\mathrm{d}}$ & $0.69 \pm 0.08^{\mathrm{d}}$
\end{tabular}

Each value is the mean of three determinations followed by standard deviation.

a Significant differences between the control/1\% Zeolite and control/2\%

Zeolite $\mathrm{p}<0.05$.

b Significant differences between the control/1\% Zeolite and control/2\%

Zeolite $\mathrm{p}<0.01$.

c Significant differences between the control/1\% Zeolite and control/2\% Zeolite $\mathrm{p}<0.001$.

d Significant differences between $1 \%$ Zeolite/2\% Zeolite $\mathrm{p}<0.05$. but has an effect on yolk color [29]. Finally, our study shows that dietary zeolite has no significant effect on ratio Yolk/albumen comparing with the control (Table 4). These results agree with previous report described by Öztürk et al. [30].

\section{Yolk fatty acid composition}

It is essential to note that from the standpoint of vascular disease prevention, n-3 PUFAs are the most important and extensively studied class of essential PUFA. n-3 and n-6 PUFAs are termed "essential" FA and must be obtained from the diet because humans lack the $\Delta 12$ and $\Delta 15$-desaturases necessary to insert a double bond at the n-3 or $n-6$ position of an FA carbon chain. The difference between the two essential PUFA is based on the location of the first double bond of the molecule counting from the methyl end of the FA [26].

As previously reported, Mallek et al. showed a positive effect of zeolite on PUFA production in broilers [13]. In the present experiment, fatty acids content was determined in egg yolks collected from control and zeolitefed hens. Addition of a natural mineral, the zeolite, was shown to increase significantly $(\mathrm{p}<0.05)$ the level of total $\mathrm{n}-3$ fatty acids in eggs fat (Table 5 ), with this response being primarily related to higher levels of linolenic acid. Similar results were also reported by Lawlor et al. [31] using fed diets containing microencapsulated fish oil. Authors showed that DHA and EPA transfer significantly $(\mathrm{p}<0.05)$ to table eggs.

It is important to note that PUFAs (linoleic acid and alpha-linolenic acid) have displayed protection against

Table $\mathbf{5}$ Effect of Zeolite dietary supplementation on fatty acid composition (\% total fatty acids).

\begin{tabular}{lccc}
\hline Fatty acids (\%) & Control & 1\% Zeolite & 2\% Zeolite \\
\hline Saturated fatty acids (SFA) & & \\
Myristic acid (C14:0) & $0.355 \pm 0.005$ & $0.33 \pm 0.00^{c}$ & $0.325 \pm 0.005^{\mathrm{c}}$ \\
Palmitic acid (C16:0) & $26.465 \pm 0.255$ & $25.925 \pm 1.505$ & $24.6 \pm 0.06$ \\
Stearic acid (C18:0) & $9.04 \pm 0.33$ & $9.025 \pm 0.785$ & $7.315 \pm 0.825^{\text {ad }}$ \\
Mono-unsaturated fatty acids (MUFA) & & \\
Palmitoleic acid (C16:1) & $3.265 \pm 0.175$ & $3.5 \pm 0.1$ & $3.925 \pm 0.285^{\mathrm{b}}$ \\
Oleic acid (C18:1) & $45.565 \pm 0.005$ & $46.79 \pm 0.35^{\mathrm{a}}$ & $47.54 \pm 0.76^{\mathrm{b}}$ \\
Poly-unsaturated fatty acids (PUFA) & & \\
Linoleic acid (C18:2) & $13.06 \pm 0.11$ & $13.29 \pm 1.08^{\mathrm{d}}$ & $15.56 \pm 0.725^{\mathrm{bd}}$ \\
Linolenic acid (C18:3) & $0.25 \pm 0.03$ & $0.275 \pm 0.035^{\mathrm{d}} 0.465 \pm 0.165^{\mathrm{ad}}$ \\
\hline
\end{tabular}

Each value is the mean of three determinations followed by standard deviation.

a Significant differences between the control/1\% Zeolite and control/2\% Zeolite $\mathrm{p}<0.05$.

b Significant differences between the control/1\% Zeolite and control/2\% Zeolite $\mathrm{p}<0.01$.

c Significant differences between the control/1\% Zeolite and control/2\% Zeolite $\mathrm{p}<0.001$.

d Significant differences between $1 \%$ Zeolite/2\% Zeolite $\mathrm{p}<0.05$. 
lipid peroxidation increasing the levels of several cellular antioxidants such as ascorbic acid, a-tocopherol and GSH [32]. In the present work, linoleic acid increased significantly $(\mathrm{p}<0.01)$ compared to the control mainly when $2 \%$ of zeolite was added.

The effects of zeolite on two monounsaturated fatty acids (MUFA) were showed in Table 5 . When $1 \%$ of Zeolite was added, the percentage of 18:1 oleic acid increased compared with control. However there is no significant increase of 16:1 palmitoleic acid percentage, again likely as a result of a reduction in $\Delta 9$ desaturase activity. Similar results were reported by Cachaldora et al. [33]. Authors showed that inclusion of $50 \mathrm{~g}$ lard $/ \mathrm{kg}$ only increased slightly the monounsaturated FA content (by $3.3 \%$ ) and had little effect on the rest of the FA profile with respect to the control diets with no fat added.

Addition of Zeolite reduced clearly the level of Myristic $(\mathrm{C} 14: 0)$ saturated fatty acid $(\mathrm{p}<0.001)$ in yolk eggs (Table 5$)$ and this was attributed to a slight reduction in C18:0 stearic acid when $2 \%$ of zeolite was added. No significant difference in C16:0 palmitic acid content was observed compared with control. Fraeye et al. reported that typically, the amount of saturated or monounsaturated fatty acids in eggs is hardly influenced by the lipids in the feed [19]. In contrast, the PUFA content and profile in the egg can be modified through dietary supplementation.

Finally, it is important to note that n-3 PUFA are susceptible to oxidation. Therefore, increasing the level of these sensitive fatty acids in egg yolk may bring about a higher extent of lipid oxidation, which could impair sensorial quality. Furthermore, lipid oxidation products can damage biological tissues and have been related to several diseases such as cancer and atherosclerosis [34]. We did not observe any differences in trans-fatty acids when zeolite was added compared to control eggs (data not shown) indicating that no oxidative damage in egg yolks was occurred during treatment.

\section{Conclusion}

Plant and animal fats contain relatively minor levels of n-3 fatty acids, with the exception of those plant oils that are rich in ALA, such as flax and canola. In order to achieve products, such as plant oils or animal fats, which contain longer chain n-3 PUFA, additional approaches are necessary [31]. One example of such an approach is the $n-3$ enriched egg.

Significant dietary effects of feeding zeolite are observed for egg height and eggshell strength at the recording period, while dietary zeolite supplementation tended to/or has no significant effects on total egg, eggshell, yolk and albumen weights. When zeolite is added, the composition of egg yolk fatty acids content is significantly modified. The present experiment shows the significance of using zeolite, as a feed additive for Laying Hens, as part of a comprehensive program to control egg quality and to increase level of polyunsaturated fatty acids on egg.

\section{Competing interests}

The authors declare that they have no competing interests.

\section{Authors' contributions}

IF, LK, ZM and, AT designed the experiments, analyzed the data and drafted the manuscript. NG and RG conceived research and approaches and have given final approval of the manuscript to be published. All authors read and approve the final manuscript.

\section{Acknowledgements}

Particular thanks were addressed to Mr Jamel Makni for CPG analyses. This work received financial support from "Ministère de l'enseignement supérieur et de la recherche et de la technologie" granted to the "Unité de recherche Toxicologie - Microbiologie environnementale et santé, Faculté des Sciences de Sfax, Université de Sfax-Tunisie.

\section{Author details}

${ }^{1}$ Unité de recherche Toxicologie - Microbiologie Environnementale et Santé (UR11ES70), Faculté des Sciences de Sfax, Université de Sfax, Sfax, Tunisia. ${ }^{2}$ Centre Vétérinaire de Recherche, Sfax, Tunisia. ${ }^{3}$ Laboratoire national de santé publique, Ouagadougou, Burkina Faso. ${ }^{4}$ Laboratoire des Biotechnologies Végétales Appliquées à l'Amélioration des Cultures, Faculté des Sciences de Sfax, Université de Sfax, Sfax, Tunisia.

\section{Received: 7 May 2012 Accepted: 19 May 2012}

Published: 7 June 2012

\section{References}

1. Muzaffer T, Demirel R, Şentürk D, Kurt D, Bacinoglu S, Cirit Ü, Ketani MA: Effects of dietary natural Zeolite on the testicular weight, body weight and spermatological characteristics in rats. J Fac Vet Med 2007, 33:33-42.

2. Papaioannou D, Katsoulos PD, Panousis N, Karatzias H: The role of natural and synthetic zeolites as feed additives on the prevention and/or the treatment of certain farm animal diseases: A review. Micropor Mesopor Mat 2005, 84:161-170.

3. Nassiri-Moghaddam $H$, Jahanian $R$, Jahanian-Najafabadi H, Madaeni MM: Influence of Dietary Zeolite Supplementation on the performance and Egg Quality of Laying Hens Fed Varying Levels of Calcium and Nonphytate Phosphorus. J Biol Sci 2008, 8:328-334.

4. Mumpton FA, Fishman PH: The application of natural zeolites in animal science and aquaculture. J Anim Sci 1977, 45:1188-1203.

5. Parlat SS, Yildiz AO, Oguz H: Effect of clinoptilolite on performance of Japanese quail (Coturnix coturnix japonica) during experimental aflatoxicosis. Br Poult Sci 1999, 40:495-500.

6. Rizzi L, Simioli M, Roncada P, Zaghini A: Aflatoxin B1 and clinoptilolite in feed for laying hens: Effects on egg quality, mycotoxin residues in livers and hepatic mixed-function oxygenase activities. J Food Prot 2003, 66:860-865.

7. Onogi T: Treating experiments of chicken droppings with zeolite-tuff. 2. Experimental use of zeolite-tuff as dietary supplements for chickens. Rep Yamagata Stock Raising Inst. 1966, 7

8. Fethiere R, Miles RD, Harms RH: The utilization of sodium zeolite $\mathrm{A}$ by broilers. Poultry Sci 1994, 73:118-121.

9. Wu-Haan W, Powers WI, Angel CR, Hale CE III, Applegate TJ: Effect of an acidifying diet combined with zeolite and slight protein reduction on air emissions from laying hens of different ages. Poult Sci 2007, 86:182-190.

10. Wen T, Zhang X, Zhang HQ, Liu JD: Ammonium removal from aqueous solutions by zeolite absorption together with chemical precipitation. Water Sci Technol 2010, 61:1941-1947.

11. Cabuk M, Alcicek A, Bozkurt M, Akkan S: Effect of Yucca schidigera and natural zeolite on broiler performance. Int J Poult Sci 2004, 3:651-654.

12. Beker A, Vanhooser SL, Swartzlander JH, Teeter RG: Atmospheric ammonia concentration effects on broiler growth and performance. J Appl Poult Res 2004, 13:5-9.

13. Mallek Z, Fendri I, Khannous L, Ben Hassena A, Traore Al, Ayadi MA, Gdoura R: Effect of Zeolite (Clinoptilolite) as additive in Tunisian broilers on the total flora, the meat texture and the production of omega 3 polyunsaturated fatty acid. Lipids Heal Dis 2012, 11:35. 
14. Molendi-Coste O, Legry V, Leclercq IA: Why and how meet n-3 PUFA Dietary Recommendations? Gastroenterol Res Pract 2011. doi:10.1155/2011/ 364040 .

15. Ansenberger K, Richards C, Zhuge Y, Barua A, Bahr JM, Luborsky JL, Hales $D B$ : Decreased severity of ovarian cancer and increased survival in hens fed a flaxseed-enriched diet for 1 year. Gynecol Oncol 2010, 117:341-347.

16. Hanf V, Gonder U: Nutrition and primary prevention of breast cancer: foods, nutrients and breast cancer risk. Eur J Obstet Gynecol Reprod Biol 2005, 123:139-149.

17. Hall MN, Chavarro JE, Lee IM, Willet WC, Ma J: A 22-year prospective study of fish, n-3 fatty acid intake, and colorectal cancer risk in men. Cancer Epidemiol Biomark Prev 2008, 17:1136-1143.

18. Fradet V, Cheng I, Casey G, Witte JS: Dietary omega-3 fatty acids, cyclooxygenase-2 genetic variation, and aggressive prostate cancer risk. Clin Cancer Res 2009, 15:2559-2566.

19. Fraeye I, Bruneel C, Lemahieu C, Buyse J, Muylaert K, Foubert I: Dietary enrichment of eggs with omega-3 fatty acids: A review. Food Res Int 2012. doi:10.1016/j.foodres.2012.03.014.

20. Hidalgo A, Rossi M, Clerici F, Ratti S: A market study on the quality characteristics of eggs from different housing systems. Food Chem 2008, 106:1031-1038.

21. Folch J, Lees M, Sloane Stanley GH: A simple method for the isolation and purification of total lipids from animal tissues. J Biol Chem 1957, 226:497509

22. Abdelkafi S, Abousalham A: The substrate specificities of sunflower and soybean phospholipases $\mathrm{D}$ using transphosphatidylation reaction. Lipids Heal Dis 2011, 10:196.

23. Abdelkafi S, Fouquet B, Barouh N, Durner S, Pina M, Scheirlinckx F, Villeneuve $\mathrm{P}$, Carrière F: In vitro comparisons between Carica papaya and pancreatic lipases during test meal lipolysis: potential use of CPL in enzyme replacement therapy. Food Chem 2009, 115:100-106.

24. Abdelkafi S, Ogata H, Barouh N, Fouquet B, Lebrun R, Pina M, Scheirlinckx F, Villeneuve $P$, Carrière F: Identification and biochemical characterization of a GDSL-motif carboxylester hydrolase from Carica papaya latex. Biochim Biophys Acta 2009, 1791:1037-1046.

25. Wang Y, Sunwoo H, Cherian G, Sim JS: Fatty Acid Determination in Chicken Egg Yolk: A Comparison of Different Methods. Poult Sci 2000, 79:1168-1171

26. Pordomingo AJ, García TP, Volpi Lagreca G: Effect of feeding treatment during the backgrounding phase of beef production from pasture on: II. Longissimus muscle proximate composition, cholesterol and fatty acids. Meat Sci 2012, 90:947-955.

27. Shariatmadari F: The application of zeolite in poultry production. World's Poultry Sci J 2008, 64:76-84.

28. Olver MD: Effect of feeding clinoptilolite (zeolite) to three strains of laying hens. Br Poult Sci 1989, 30:115-121.

29. Kermanshahi H, Haji Agha Jani E, Hashemipour H, Pilevar M: Efficacy of natural zeolite and pigments on yolk color and performance of laying hens. Afr J Biotechnol 2011, 10:3237-3242.

30. Öztürk E, Erener G, Sarica M: Influence of Natural Zeolite on Performance of Laying Hens and Egg Quality. Tr J Agric Forest 1998, 22:623-628.

31. Lawlor JB, Gaudette N, Dickson T, House JD: Fatty acid profile and sensory characteristics of table eggs from laying hens fed diets containing microencapsulated fish oil. Anim Feed Sci Technol 2010, 156:97-103.

32. Nagao $T$, Komine $Y$, Soga $S$, Meguro $S$, Hase T, Tanaka Y, Tokimitsu I: Ingestion of a tea rich in catechins leads to a reduction in body fat and malondialdehyde-modified LDL in men. Am J Clin Nutr 2005, 81:122-129.

33. Cachaldora P, Garcia-Rebollar P, Alvarez C, De Blas JC, Méndez J: Effect of type and level of basal fat and level of fish oil supplementation on yolk fat composition and $\mathrm{n}-3$ fatty acids deposition efficiency in laying hens. Anim Feed Sci Technol 2008, 141:104-114.

34. Aymond WM, Van Elswyk ME: Yolk thiobarbituric acid reactive substances and $\mathrm{n}-3$ fatty-acids in response to whole and ground flaxseed. Poult Sci $1995,74: 1388-1394$

doi:10.1186/1476-511X-11-71

Cite this article as: Fendri et al:: Influence of Zeolite on fatty acid composition and egg quality in Tunisian Laying Hens. Lipids in Health and Disease 2012 11:71.

\section{Submit your next manuscript to BioMed Central and take full advantage of:}

- Convenient online submission

- Thorough peer review

- No space constraints or color figure charges

- Immediate publication on acceptance

- Inclusion in PubMed, CAS, Scopus and Google Scholar

- Research which is freely available for redistribution 